\title{
Genetic and non genetic effects for lactation curve traits in Holstein-Friesian cows
}

\author{
Ismaïl Boujenane and Btissam Hilal
}

Department of Animal Production and Biotechnology, Institut Agronomique et Vétérinaire Hassan II, Rabat, Morocco

\begin{abstract}
The objective of this study was to determine the genetic and non genetic effects on lactation curve traits determined by the incomplete gamma function of Wood (1967) for HolsteinFriesian cows in Morocco. Data analysed included 49262 monthly records of the test-day milk yield from 4888 lactations of 3932 cows at their 1st, 2nd or 3rd parity collected during 1990 and 1999 in 232 herds enrolled in the official milk recording. In general, lactation curve traits $\left(A, B, C\right.$, peak time $\left[T_{\max }\right.$, peak milk yield $\left[Y_{\max }\right.$, persistency and 305 day milk yield [MY305]) were affected by herd, parity, age at calving, season of calving and year of calving. Heritability estimates were low and varied from 0.01 for parameter $A$ to 0.10 for $\mathrm{Y}_{\max }$. Genetic and phenotypic correlations among traits varied from -0.79 to 1.00 and from -0.80 to 0.96 , respectively. Genetic correlations between MY305 and parameter $C$ were negative, but those between MY305 and all the other lactation curve traits were positive. It was concluded that selection for high peak milk yield and persistency will result in higher 305 day milk yield.
\end{abstract}

Keywords: cows, lactation curve, incomplete gamma function, milk yield at peak , environmental effects, heritability

\section{Introduction}

The introduction of high dairy cows in Morocco started at the beginning of 1970s. More than 5000 Holstein-Friesian heifers were introduced annually. Moreover, besides this introduction, a grading up program of local cows was adopted that increased the frequency of HolsteinFriesian genes in the Moroccan cattle population. At present, a large Holstein-Friesian population of several thousands cows was constituted. This genetic pool was subjected to some studies dealing with reproduction and production traits (Boujenane \& Maty 1986, Boujenane \& Aïssa 2008) and estimation of genetic parameters (Boujenane 2002), in order to improve production traits under Moroccan conditions. Furthermore, some authors have assessed the inclusion of lactation curve traits such as peak milk yield and persistency as selection criteria to improve total milk yield (Batra et al. 1987). However, there are no estimates available for the genetic covariances that involve lactation curve traits in Moroccan dairy cattle.

The aim of this study was to fit and estimate the traits of lactation curves of Holstein-Friesian cows in Morocco using incomplete gamma function, to investigate the environmental factors affecting lactation curve traits and to estimate their genetic and phenotypic parameters (heritabilities, repeatabilities, and genetic and phenotypic correlations). 


\section{Material and methods}

\section{Origin of data}

The records initially analysed included 77525 monthly records of the test-day milk production data from Holstein-Friesian cows collected between 1990 and 1999 in 280 farms located at different regions of the country and enrolled in the official milk recording classified as type A. These data were obtained from cows at their 1st, 2nd and 3rd parity, with age at calving ranging from 24 to 48,36 to 60 and 48 to 72 months, respectively. They were restricted to records for which the first milk recording had occurred between 5 and 50 days (Wilmink 1987), spacing of consecutive sample days was not more than 60 days and lactation length greater than 305 days. However, when the lactation of a cow was longer than 305 days, records were truncated at 305 days in milk (DIM). Furthermore, milk yield less than $3 \mathrm{~kg}$ or greater than $60 \mathrm{~kg}$ per day was discarded. All cows were milked twice a day.

\section{Data analyses}

The mathematical model fitted was Wood incomplete gamma function (Wood 1967):

$$
y_{t}=A t^{B} \exp ^{-C t}
$$

where $t$ denotes day in milking, $y_{t}$ denotes daily milk yield on day $t$ of lactation, $A$ is a general scaling factor representing initial yield, $B$ and $C$ are factors associated with the inclining and declining slope of the lactation curves, respectively. Initially, parameters $A, B$ and $C$ were first estimated by fitting the Wood's function in form of log-linear. Atypical lactations with negative parameters $B$ or $C$, as well as herds with less that two cows were discarded. Approximately, $32.7 \%$ of the lactations analysed were excluded because of atypical shape. The remaining typical lactations with respect to Wood's description were then analysed by the non-linear regression using the NLIN procedure and the Marquardt iterative method of SAS v. 9 (SAS Institute Inc., Cary, NC, USA). Lactation curve parameters obtained from the linearised form were used as starting grids. Moreover, individual cow lactation curve parameters obtained from the non-linear regression were used to compute peak time:

$$
T_{\max }=\frac{B}{C}
$$

peak milk yield at the peak time:

$$
Y_{\max }=A\left(\frac{B}{C}\right)^{B} \exp ^{-B}
$$

persistency:

$$
\text { PERS }=(-B+1) \ln C
$$

and 305-d milk yield calculated for each lactation by adding the daily milk yield predicted from the model from day 1 to day 305 as:

$$
\text { MY305 }=\sum_{t=1}^{305} A t^{B} \exp ^{-C t}
$$


After editing all data, final analyses were performed using a pedigree file with 8068 animals (individuals, sires and dams) and a production file from 4888 lactations with 49262 test day milk yields from 3932 cows raised in 232 farms.

Individual cow lactation curve traits obtained were subjected to statistical analyses. They were first analysed by least-squares analysis of variance using MIXED procedure of SAS v. 9 (SAS Institute Inc., Cary, NC, USA) to determine the significance of the fixed effects to include in the model for genetic parameter estimation. The statistical model for lactation curve traits included the random effect of cow and the fixed effects of herd (232 herds), parity (1, 2 and 3), age at calving ( $\leq 30$ months, $>30$ to $\leq 42$ months, and $>42$ months), calving season (October through April and May through September), and year of calving $(1990, \ldots, 1999)$. First order interactions between effects were not tested and hence were assumed to be negligible.

Variance components for individual cow lactation curve traits were estimated for each trait separately with derivative-free REML procedures using the MTDFREML program of Boldman et al. (1995). The basic single trait repeatability model in matrix notation was:

$$
y=X b+Z a+W p e+e
$$

where $y$ is a vector of observations, $\boldsymbol{b}$ is a vector of fixed effects with incidence matrix $X$, $a \sim N\left(0, A \sigma_{a}^{2}\right)$ is a vector of random animal effects with incidence matrix $Z, p e \sim N\left(0, I_{c} \sigma_{p e}^{2}\right)$ is a vector of random permanent environmental effects with incidence matrix $W$, and $e \sim N(0$, $I_{n} \sigma_{e}^{2}$ ) is a vector of random residual effects. $\sigma_{a}^{2}$ is the additive genetic variance, $\sigma_{p e}^{2}$ is the permanent environmental variance, $\sigma_{e}^{2}$ is the residual variance, $A$ is the additive genetic relationship matrix, and $I_{c}$ and $I_{n}$ are identity matrices of order equal to the number of cows and the number of records, respectively.

Convergence of the derivative-free iterative process was considered reached when the variance of simplex values ( -2 log likelihood) was less than $10^{-8}$. To ensure a global maximum, each analysis was restarted with previous converged values until the estimated value of the -2 log-likelihood function did not differ in its first three decimal places. Solutions for fixed and random effects were from the last round of iteration in which the global maximum was achieved.

Similar derivative-free REML procedures were used for bivariate analyses to estimate covariance components and correlations between traits. The model included the same fixed effects and the animal effects only. Estimates from single-trait analyses were used to obtain starting values for bivariate analyses. Convergence was first obtained when the simplex variance was less than $10^{-3}$ and then when the simplex variance was less than $10^{-6}$.

\section{Results and discussion}

\section{General}

In lactation curves investigated in this study, percent of atypical lactations (parameter B or C negative) was found to be $32.7 \%$. Among them, $31.8 \%$ lactations for parameter of $B$ and $16.1 \%$ lactations for parameter of $C$ had negative estimates and $15.9 \%$ lactations had both $B$ and $C$ negative. These curves were assumed to correspond to cows with problems because of lack of information, erroneous data or management problems. The occurrence of atypical shapes, characterised by the absence of the lactation peak, occured in about 15-42\% (Tekerli et al. 2000, Rekik et al. 2003, Soysal et al. 2005, Atashi et al. 2009). Only Shanks et al. (1981) reported a low proportion; 840 atypical lactations of 113705 lactations. 
The descriptive statistics for the studied traits are reported in Table 1. Milk yield increased from calving to the peak milk yield of $23.6 \mathrm{~kg}$ that was reached at day 41.4 , and then decreased gradually until dry off with a persistency of 6.56 . The proportion of milk yield produced from calving to the lactation peak represented $10.6 \%$ of the milk yield produced during 305 day lactation. Likewise, milk yield produced from calving to day 100, from day 101 to day 200, and from day 201 to day 305 represented $28.7 \%, 33.6 \%$ and $37.7 \%$ of the 305 lactation milk yield, respectively.

Table 1

Descriptive statistics for traits studied in Holstein-Friesian cows in Morocco

\begin{tabular}{lcccc}
\hline & Number & $\begin{array}{c}\text { Arithmetic } \\
\text { mean }\end{array}$ & $\begin{array}{c}\text { Standard } \\
\text { deviation }\end{array}$ & $\begin{array}{c}\text { Coefficient } \\
\text { of variation, \% }\end{array}$ \\
\hline Age at calving, mo. & 4888 & 39.1 & 11.5 & 29.4 \\
Daily milk yield, kg & 4888 & 20.7 & 6.63 & 32.0 \\
A & 4888 & 17.0 & 2.62 & 15.4 \\
$\mathrm{~B}$ & 4888 & 0.1039 & 0.0604 & 58.1 \\
$\mathrm{C}$ & 4888 & 0.0029 & 0.0013 & 44.8 \\
$\mathrm{~T}_{\text {max }}$ days & 4888 & 41.4 & 20.8 & 50.2 \\
$Y_{\text {max }}$ kg & 4888 & 23.6 & 5.55 & 23.5 \\
PERS & 4888 & 6.56 & 0.48 & 7.32 \\
MY305, kg & 4888 & 8946.4 & 3142.9 & 35.1 \\
\hline
\end{tabular}

\section{Environmental effects}

The least-square means for group effects of parity, age at calving and season of calving for the lactation curve traits are shown in Table 2. Parity significantly influenced all lactation curve traits studied, resulting in curves of similar shapes but different production levels. Parameters $A, B, C$, $Y_{\max }$ and MY305 increased with parity, whereas $T_{\max }$ and persistency decreased as parity increased. The results showed that the first lactation had the lowest $A$, the lowest $B$ and the lowest $C$. Multiparous cows reached their peak of production earlier in the lactation than first parity cows (35.6th day of lactation). Likewise, the highest persistency was for the first parity cows.

Table 2

Least-square means for lactation curve traits of Holstein-Friesian cows

\begin{tabular}{lcccccccc}
\hline Fixed effects & Number & & \multicolumn{7}{c}{ Lactation curve traits } \\
& & $\mathrm{A}$ & $\mathrm{B}$ & $\mathrm{C}$ & $\mathrm{T}_{\max }$ & $\mathrm{Y}_{\max }$ & PERS & MY305 \\
\hline Parity & & $* * *$ & $* * *$ & $* * *$ & $*$ & $* * *$ & $* * *$ & $* * *$ \\
1 & 2431 & 15.9 & 0.073 & 0.0026 & 35.6 & 20.0 & 6.51 & 7135.1 \\
2 & 1541 & 16.9 & 0.091 & 0.0031 & 33.1 & 22.6 & 6.40 & 8529.0 \\
3 & 916 & 17.2 & 0.096 & 0.0033 & 32.1 & 23.4 & 6.36 & 8983.0 \\
Age, months & & $*$ & $* *$ & $\mathrm{~ns}$ & $*$ & $* * *$ & $\mathrm{~ns}$ & $* * *$ \\
Age $\leq 30$ & 1651 & 16.6 & 0.082 & 0.0030 & 32.5 & 21.5 & 6.42 & 7931.1 \\
$30<$ Age $\leq 42$ & 1510 & 16.6 & 0.086 & 0.0030 & 32.9 & 21.9 & 6.42 & 8171.2 \\
42<Age $\leq 72$ & 1727 & 16.9 & 0.092 & 0.0031 & 35.3 & 22.6 & 6.44 & 8544.8 \\
Calving season & & $*$ & $* * *$ & $* * *$ & $\mathrm{~ns}$ & $* * *$ & $* * *$ & $* * *$ \\
Oct.-April & 1970 & 16.6 & 0.080 & 0.0028 & 34.0 & 21.5 & 6.46 & 7889.0 \\
May-Sept. & 2918 & 16.8 & 0.093 & 0.0032 & 33.2 & 22.5 & 6.39 & 8542.4 \\
\hline
\end{tabular}

${ }^{*} P<0.05,{ }^{*} P<0.01,{ }^{*}{ }^{*} P<0.001$, ns: not significant, $P>0.05$ 
Age at calving had significant effects on parameters $A, B, T_{\text {max }} Y_{\text {max }}$ and MY305, but not on parameter $C$ and persistency. The youngest cows had lowest $A, B, Y_{\max }$ and MY305, but the highest $T_{\max }$.

Considering the season of calving, peak milk yield was higher in those cows calving from May to September compared with those calving from October to April, but the peak occurrence was similar for cows calving in both seasons. Likewise, persistency was higher for cows calving from October to April compared to those calving from May to September. The season effect demonstrated that the higher initial production level, the higher the peak milk yield with slower rate of decline.

Noteworthy, herd and year of calving significantly influenced lactation curve traits owing to herd management differences and yearly change of production factors. Keown et al. (1986) reported that the cows that are raised in higher yielding herds have higher peak production and more persistency when compared with low herd production cows.

The effects of environmental factors on lactation curve traits found in this study are in agreement with the results reported in the literature (Tekerli et al. 2000, Rekik et al. 2003, Amin 2007, Atashi et al. 2009). The significant environmental effects may have practical implications in determining optimal feeding management and season of breeding to maximise total lactation yield.

\section{Genetic and phenotypic effects}

Variance components, heritability and repeatability estimates for lactation curve traits are presented in Table 3. Heritability estimates for lactation curve traits were low and ranged from 0.01 for parameters $\mathrm{A}$ and $\mathrm{C}$ to 0.10 for milk yield at lactation peak. Additionally, heritabilities computed as the average values from all bivariate analyses were almost similar to those estimated from single trait analyses. The low heritability estimates for lactation curve traits suggest that such traits are mainly dependent on environmental variation. The heritability estimates for parameters A, B and C are in agreement with those reported by Batra et al. (1987) and Farhangfar \& Rowlinson (2007). However, Farhangfar \& Rowlinson (2007) and López-Ordaz et al. (2009) reported estimates that are greater for $Y_{\max }(0.28), T_{\max }(0.11$ and $0.17)$ and MY305 (0.30 and 0.28). Heritability estimate for persistency was close to those reported by Atashi et al. (2006) and Farhangfar \& Rowlinson (2007), and slightly higher than that reported by Shanks et al. (1981). Muir et al. (2004), using first parity data in Holstein, found heritabilities of 0.45 for MY305, 0.09 for $\mathrm{T}_{\max }$ and 0.18 for the persistency defined as the slope of the lactation curve after peak production. Rekaya et al. (2000), using first parity data, found heritabilities as $0.26,0.14,0.26$, and 0.05 for MY305, persistency, $Y_{\max }$ and $T_{\text {max }}$, respectively.

Repeatability estimates for lactation curve traits were also low and close to heritability estimates, owing to the low permanent environmental effects. López-Ordaz et al. (2009) reported that repeatability for $Y_{\max }$ was 0.24 , similar to the estimates by Rekaya et al. (2000) and Tekerli et al. (2000), as 0.26 . The repeatability for persistency was 0.15 (López-Ordaz et al. 2009) and 0.18 (Tekerli et al. 2000).

Genetic and phenotypic correlations among lactation curve traits are presented in Table 4. Genetic correlations varied from -0.79 to 1.00 and phenotypic correlations ranged from -0.80 to 0.96 . Genetic correlations between lactation curve parameters $\left(A, B, T_{\text {max }} Y_{\text {max }}\right.$ and PERS) and 305-d milk yield were positive, but those between parameter $C$ on one hand and $A, Y_{\text {max }}$ persistency and MY305 on the other hand were negative. 
Table 3

Variance components, heritability and repeatability estimates for lactation curve traits

\begin{tabular}{lccccclc}
\hline Parameter $^{\mathrm{a}}$ & & \multicolumn{5}{c}{ Lactation curve traits } \\
& $\mathrm{A}$ & $\mathrm{B}$ & \multicolumn{1}{c}{$\mathrm{C}$} & $\mathrm{T}_{\max }$ & $\mathrm{Y}_{\max }$ & PERS & MY305 \\
\hline$\sigma_{\mathrm{a}}^{2}$ & 0.04 & $0.11 \times 10^{-3}$ & $1.18 \times 10^{-8}$ & 18.3 & 1.48 & 0.006 & 414289 \\
$\sigma_{\mathrm{ep}}^{2}$ & 0.04 & $1.19 \times 10^{-8}$ & $1.00 \times 10^{-8}$ & 0.016 & 0.271 & $6.57 \times 10^{-8}$ & 1.71 \\
$\sigma_{\mathrm{e}}^{2}$ & 4.69 & $1.84 \times 10^{-3}$ & $1.16 \times 10^{-6}$ & 285.6 & 12.9 & 0.138 & 4188923 \\
$\sigma_{\mathrm{p}}^{2}$ & 4.77 & $1.95 \times 10^{-3}$ & $1.18 \times 10^{-6}$ & 304.0 & 14.4 & 0.144 & 4603212 \\
$\mathrm{~h}^{2}$ & 0.01 & 0.05 & 0.01 & 0.06 & 0.10 & 0.05 & 0.09 \\
$\mathrm{t}$ & 0.02 & 0.06 & 0.02 & 0.06 & 0.10 & 0.05 & 0.09 \\
\hline
\end{tabular}

${ }^{\mathrm{a}} \sigma_{\mathrm{a}}^{2}$ : additive genetic variance, $\sigma_{\mathrm{ep}}^{2}$ :permanent environment variance, $\sigma_{\mathrm{e}}^{2}$ : residual variance, $\sigma_{\mathrm{p}}^{2}$ : phenotypic variance, $\mathrm{h}^{2}=\frac{\sigma_{\mathrm{a}}^{2}}{\sigma_{\mathrm{p}}^{2}}=$ heritability, $\mathrm{t}=\frac{\sigma_{\mathrm{a}}^{2}+\sigma_{\mathrm{ep}}^{2}}{\sigma_{\mathrm{p}}^{2}}=$ repeatability.

Table 4

Estimates of genetic correlations, phenotypic correlations and heritabilities among lactation curve traits in Holstein-Friesian cows from bivariate analyses ${ }^{1}$

\begin{tabular}{lrrrrrrr}
\hline & \multicolumn{7}{c}{ Lactation curve traits } \\
& $\mathrm{A}$ & $\mathrm{B}$ & \multicolumn{1}{c}{$\mathrm{C}$} & $\mathrm{T}_{\max }$ & $\mathrm{Y}_{\max }$ & PERS & MY305 \\
\hline $\mathrm{A}$ & $\mathbf{0 . 0 2}$ & 0.66 & -0.79 & 1.00 & 0.76 & 1.00 & 0.67 \\
$\mathrm{~B}$ & -0.19 & $\mathbf{0 . 0 5}$ & 0.38 & 0.99 & 0.96 & 0.47 & 1.00 \\
$\mathrm{C}$ & 0.18 & 0.63 & $\mathbf{0 . 0 2}$ & 0.38 & -0.19 & -0.55 & -0.17 \\
$\mathrm{~T}_{\max }$ & -0.37 & 0.32 & -0.38 & $\mathbf{0 . 0 6}$ & 1.00 & 0.75 & 1.00 \\
$\mathrm{Y}_{\max }$ & 0.55 & 0.67 & 0.51 & 0.13 & $\mathbf{0 . 1 0}$ & 0.81 & 0.98 \\
PERS & -0.32 & -0.14 & -0.80 & 0.77 & -0.19 & $\mathbf{0 . 0 5}$ & 0.89 \\
MY305 & 0.38 & 0.81 & 0.65 & 0.05 & 0.96 & -0.25 & $\mathbf{0 . 0 8}$ \\
\hline
\end{tabular}

${ }^{1}$ Heritabilities, on diagonal, are the average values from all bivariate analyses. Genetic correlations above diagonal and phenotypic correlations below diagonal.

Therefore, animals that have a higher initial level of production (A parameter) will attain the peak faster and thereafter decline at a slower rate than those with a lower initial level of production. The strong negative genetic correlation between parameters $A$ and $C$ suggests that cows selected for high initial milk yield may be highly persistent in milk production. This is because lactation persistency is negatively correlated with rate of decline. From the genetic point of view, MY305 and $Y_{\text {max }}$ are practically the same variable with a genetic correlation close to 1. Farhangfar \& Rowlinson (2007) and López-Ordaz et al. (2009) obtained a similar value and Rekaya et al. (2000) a value of 0.90 . Additionally, the genetic correlation between persistency and MY305 was 0.89 . This value is higher to the estimate by Rekaya et al. (2000), 0.33 and Farhangfar \& Rowlinson (2007), 0.53 using first parity data. Thus, positive correlation of MY305 with $\mathrm{T}_{\text {max }} \mathrm{Y}_{\max }$ and persistency suggest that selection for higher producing cows will lead to higher peak yield, greater persistency and later peak time. On the other hand, studies investigated the genetic aspects of persistency, found heritability estimates to be of moderate size ( 0.1 to 0.2 ) and zero to positive genetic correlation with the 305 day milk yield. Analysis of relationship between persistency and other traits shows that genetic improvement for persistency is possible.

Phenotypic correlation between $A$ and $T_{\max }$ and correlation between $A$ and persistency were negative and medium, while correlation between $A$ and $Y_{\max }$ was positive and medium. 
If cows started lactation with high milk yield, maximum daily milk yield will be high, however, persistency will be lower. In this study, the phenotypic correlation between $\mathrm{Y}_{\max }$ and $T_{\max }$ was positive and low. Farhangfar \& Rowlinson (2007) found it equal to zero. According to previous studies (Atashi et al. 2009, Seangjun et al. 2009), phenotypic correlation between $\mathrm{Y}_{\max }$ and $\mathrm{T}_{\max }$ was negative indicating that cows with high daily milk yield reach the maximum daily milk yield early. Therefore, cows that have a higher initial level of production, higher peak milk and decline at a slower rate will have a high 305 day milk yield.

In conclusion, factors influencing lactation curve traits of Moroccan Holstein-Friesian cows were herd, parity, age at calving, season of calving and year of calving. Additionally, heritabilities obtained in this study confirm that lactation curve traits have a small genetic variation. However, despite the low heritabilities, there is still potential for improvement through selective breeding. $Y_{\max }$ had the highest heritability and had high and positive genetic correlation with 305 day milk yield, which indicates that increasing $Y_{\max }$ will increase 305 day milk yield as well.

\section{References}

Amin AA (2007) Genetic and permanent environmental variations in daily milk yield and milk flow rates in Hungarian Holstein Friesian. Arch Tierz 50, 535-548

Atashi H, Moradi Sharbabak M, Abdolmohammadi A (2006) Study of some suggested measures of milk yield persistency and their relationships. Int J Agric Biol 3, 387-390

Atashi H, Moradi Sharbabak M, Moradi Sharbabak H (2009) Environmental factors affecting the shape components of the lactation curves in Holstein dairy cattle of Iran. Livest Res Rural Dev 21, Art. 60. http:// www.Irrd.org//rrd21/5/atas21060.htm [last accessed 17.09.2012]

Batra TR, Lin CY, McAllister AJ, Lee AJ, Roy GL, Vesely JA, Wauthy JM, Winter KA (1987) Multitrait estimation of genetic parameters of lactation curves in Holstein heifers. J Dairy Sci 70, 2105-2111

Boldman KG, Kriese LA, Van Vleck LD, Van Tassell CP, Kachman SD (1995) A manual for use of MTDFREML. A set of programs to obtain estimates of variances and covariances [DRAFT]. US Department of Agriculture, Agricultural Research Service. Nebraska, USA

Boujenane I (2002) Estimates of genetic and phenotypic parameters for milk production in Moroccan HolsteinFriesian cows. Revue Elev Med Vet Pays Trop 55, 63-67

Boujenane I, Ba M (1986) [The performances of Moroccan Holstein-Friesian cows on breeding and milk production]. Rev Elev Med Vet Pays Trop 39, 145-149 [in French]

Boujenane I, Aïssa H (2008) [Reproductive and milk performances of Holstein and Montbeliarde cows in Morocco]. Rev Elev Med Vet Pays Trop 61, 191-196 [in French]

Farhangfar H, Rowlinson P (2007) Genetic analysis of Wood's lactation curve for Iranian Holstein heifers. J Biol Sci 7, 127-135

Keown JF, Everett RW, Empet NB, Wadell LH (1986) Lactation curves. J Dairy Sci 69, 769-781

López-Ordaz R, Castillo-Juárez H, Montaldo HH (2009) [Genetic and phenotypic covariances for days open and lactation curve characteristics in Holstein cows from northern Mexico]. Vet Mex 40, 343-356 [in Spanish]

Muir BL, Fatehi J, Schaeffer LR (2004) Genetic relationships between persistency and reproductive performance in first-lactation Canadian Holsteins. J Dairy Sci 87, 3029-3037

Rekaya R, Carabaño MJ, Toro MA (2000) Bayesian analysis of lactation curves of Holstein-Friesian cattle using a nonlinear model. J Dairy Sci 83, 2691-2701

Rekik B, Ben Gara A, Ben Hamouda M, Hammami H (2003) Fitting lactation curves of dairy cattle in different types of herds in Tunisia. Livest Prod Sci 83, 309-315 
SAS (2002) SAS User's Guide, Statistics, Version 9, SAS Institute Inc., Cary, NC, USA

Seangjun A, Koonawootrittriron S, Elzo MA (2009) Characterization of lactation patterns and milk yield in a multibreed dairy cattle population in the Central Thailand. Kasetsart J Nat Sci 43, 74-82

Shanks RD, Berger PJ, Freeman AE, Dickinson FN (1981) Genetic aspects of lactation curves. J Dairy Sci 64, 1852-1860

Soysal MI, Mutlu F, Gurcan EK (2005) A study of the lactation biometry of Black and White dairy cows raised in private farms in Turkey. Trakia J Sci 3, 11-16

Tekerli M, Akinci Z, Dogan I, Akcan A (2000) Factors affecting the shape of lactation curves of Holstein cows from the Balikesir Province of Turkey. J Dairy Sci 83, 1381-1386

Wilmink JBM (1987) Adjustment of test day-milk, fat and protein yield for age, season and stage of lactation. Livest Prod Sci 16, 335-348

Wood PDP (1967) Algebraic model of lactation curve in cattle. Nature 216, 164-165

Received 22 December 2011, accepted 23 April 2012.

Corresponding author:

Ismaïl Boujenane

email: i.boujenane@iav.ac.ma

Department of Animal Production and Biotechnology, Institut Agronomique et Vétérinaire Hassan II, PO Box 6202 Rabat-Instituts, 10101 Rabat, Morocco 